\title{
REVENDO O NASCIMENTO DOS MUSEUS NO BRASIL
}

O atual momento histórico exige reflexão acerca do papel que vem sendo desempenhado pelas ciências humanas na produção do saber. É dentro desse contexto que surgem algumas publicaçōes de consulta obrigatória, como o primeiro volume da História das Ciências Sociais no Brasil, organizado por Sérgio Miceli (1989), As Ciências no Brasil, de Fernando de Azevedo (1966) e a História da Inteligência Brasileira, de Wilson Martins (1977). Empreendimentos de tal natureza demandam necessariamente um longo periodo de maturação, pois mais do que a construção de uma visão crítica, permitem a compreensão das ciências sociais no seu conjunto, através de uma análise histórica.

Entre os estudos publicados no primeiro volume da História das Ciências Sociais no Brasil, o capitulo de Liliam K. M. Schwarcz, "O nascimento dos museus brasileiros 1870 $1910 "$, interessa particularmente aos estudiosos de cultura material e em especial aos que se dedicam à análise dos processos de formação das instituiçōes científicas do final do século XIX e inicio do XX. Trata-se de um texto que tem por objetivo pensar os processos de formação dos museus brasileiros no âmbito da história das ciências sociais, situando essas instituiçōes num amplo contexto e mostrando o destaque que estas tiveram no passado. Pela primeira vez, tentou-se oferecer uma visão de conjunto dos museus brasileiros, pois, até aqui, pouco se escreveu além de artigos esparsos ou trabalhos acadêmicos de circulação restrita. ${ }^{1}$

(*) Museu Paulista da Universidade de São Paulo.

(1) É necessário ressaltar a importante contribuição da museóloga Waldisa Rússio Guarnieri nos anos setenta, em artigo publicado pelo Suplemento Literário de $O$ Estado de S.Paulo, em 22/7/1979, "Existe um passado museológico brasileiro?", onde ela arrola uma bibliografia até então pouco conhecida: Brasil 1960, ediçāo do Ministério das Relaçōes Exteriores, resultado de grupo de trabalho chefiado por Francisco Gualberto de Oliveira;
No entanto, alguns pontos tocados pela autora merecem uma rediscussão. Se por um lado, a visão de conjunto tem vantagens, por outro ela corre os riscos de uma excessiva generalização. Dada a nossa familiaridade com o objeto, o texto suscitou-nos questões que nos convidam ao diálogo, refletindo sobre a trajetória dos museus no Brasil.

Logo na introdução do capitulo, a autora delimita os procedimentos metodológicos que serão observados no texto e esclarece a perspectiva histórica do tratamento do tema, além de expor as principais fontes de informação $e$ elencar as publicações. Ao mesmo tempo, propõe uma forma de conceituar as instituições e uma maneira de explicar suas origens e influências recebidas.

Ao discorrer sobre a formação dos museus europeus, onde, de uma certa forma, podemos buscar os modelos para a conceituação e organização dos museus brasileiros, Schwarcz considera a criação dos Museus Nacionais, como o Louvre e o Prado, um movimento estatal de postura acumulativa e "conquistadora", tipicamente burguesa, dos Cabinets de Curiosités. No entanto, quanto ao primeiro caso (dos $\mathrm{Mu}$ seus Nacionais), a criação dessas instituiçōes serviu para demonstrar tanto a unidade (o Estado Nacional), quanto a força do poder que une a Nação (Casa Reinante, Parlamento etc.); força demonstrada na ostentação de riqueza, cultura e saber. O segundo caso, dos Cabinets de Curiosités, insere-se no movimento paulatino de conquista do espaço físico, cultural e político da burguesia; demonstra não aprisionamento do saber, mas do universo circundante, na sua maior extensão possivel, nas mãos

prefácio do Ministro Horácio Lafer, Wladimir Alves de Souza, Iniciação à Cultura Brasileira (o texto citado é do volume IV) e Grace L. Mac Cann Morley, "Les musées en Amérique Latine", in Museum, vol. XII, $\mathrm{n}^{\circ}$ 4, 1959 e Aspectos da Políica Cultural Brasileira, ediçào do Conselho Federal de Cultura, Rio de Janeiro, 1976. 
do colecionador. Quanto ao Museu do Louvre, embora o tenha considerado criação da Revolução, pode-se dizer que a Revolução Francesa não o criou, mas serviu como agente facilitador do acesso do público aos museus (Suano, 1990). Segundo alguns autores, entendemos o gabinete de curiosidades como um desejo dos séculos XVI e XVII de alcançar a totalidade, a universalidade, ou ainda conforme $\mathrm{K}$. Pomian de reunir fragmentos selecionados do universo, numa tentativa de inventarium (Pomian, 1982; Morse, 1988; Impey e MacGregor, 1985). ${ }^{2}$

No que diz respeito à diferenciação, no final do século XIX entre Museus Cientificos e Museus Artisticos, haveria necessidade de mais informações para o esclarecimento do assunto (Pradel, 1961; Hamy, 1988 e 1989). O século XIX conhece a instauração maciça das ciências, que podemos chamar de "novas", como a Quimica, a Antropologia, a Etnologia, a Lingüistica, a Sociologia. Mesmo as ciências mais antigas transformaram-se, sofisticaram-se de tal maneira a partir do fim do século XVIII, que podemos considerá-las também novas. Assim é com a Física, a Biologia, a Zoologia, a Botânica etc. Todo esse movimento insere-se no processo agudo de racionalização do pensamento e conseqüente apreensão racional do real, que está no bojo das transformaçōes sócio-econômico-culturais do periodo pós-iluminista.

Referindo-se ao século XIX, o texto ressalta a dificuldade na obtenção de verbas para os museus etnográfico-antropológicos de todo o mundo e o suposto refluxo de "imperialismo": "é o momento mesmo de perda das colônias que favorece a reposição dos objetos e a recriação desses museus, que acabam por

(2) Neste texto, Pomian analisa os Gabinetes de Curiosidades como locais onde se reúnem as grandes categorias de seres e de coisas, conhecidas na Renascença e no século XVII, orientado por um pensamento anterior à revolução,cientifica que irá ocorrer na Europa nos primórdios do século XVIII. Sobre a revolução cientifica européia da época modema pode-se consultar a análise de Richard Morse em Espelho Próspero - Cultura e Idéias nas Américas. Sobre a organização dos Gabinetes de Curiosidades, seus inventários e categorias de objetos pode-se ver O. Impey e A. MacGregor (Eds.), "The Origin of Museuns - The Cabinets of Curiosities in Sixteen and Seventeenth Centuries in Europe". expor e fetichizar todo o mundo extra-europeu" (Schwarcz, 1989:25). Desconsidera o neo-colonialismo levado a cabo pelas potências européias (Inglaterra, França, Alemanha e mesmo Bélgica, Dinamarca e Itália), que neste momento estão vivendo a expansão na busca de novos territórios.

Quanto à análise exposta em subtítulo " $\mathrm{A}$ era dos Museus no Brasil", notamos informaçōes relevantes: a postura de subserviência dos museus brasileiros aos modelos europeus e norte-americanos; a postura coletora-classificatória e tipológica - esta última é a caracteristica mais importante, embora não citada pela autora - dos viajantes estrangeiros, que vinham ao Brasil estudar a flora, a fauna, a etnologia, etc. (Schwarcz, 1989:26), pois não havia incentivo do governo para expediçōes nacionais: o que se via era diletantismo e improvisação.

A partir de 1880 , há no Brasil um amplo movimento na direção da institucionalização da pesquisa científica, congregando centros tradicionais: as Faculdades de Direito (São Paulo e Olinda), a Faculdade de Medicina da Bahia e novas Instituiçōes; os Institutos Históricos e os Museus Paraense, Paulista e Nacional. Afirma que esta efervescência surge da introdução de novas idéias, a partir de 1870, no Brasil: o evolucionismo e o naturalismo. Poderíamos incorporar no rol dessas instituiçōes o Museu Paranaense que, apesar da suá trajetória acidentada, não foi lembrado.

Essa Instituição, criada em 1874 por particulares e pela Associação Paranaense de Aclimação, mostra-se bastante ativa na segunda metade do século XIX e início do XX. Como evidencia a sua participação na Exposição Antropológica Brasileira, realizada no Museu Nacional do Rio de Janeiro, em 1882, acompanhada de três estudos: "Pequeno Vocabulärio da Língua Caingangue, dos Caiguás e Chavantes" de autoria de Telêmaco Borba, "Memória sobre os Índios Coroados ou Camés" por Frei Luiz de Cemetille e uma brochura, "Os índios da Provincia do Paraná" por Antônio Ricardo Lustosa de Andrade; consta também na Exposição de Berlim, onde funcionava como instrumento para incentivar a imigração alemã para o Paraná; aparece em 1900 , oferecendo um catálogo de suas exposições, detalhadamente descritas em suas várias seções: arqueologia, etnologia, história, 
numismática, jardim zoológico (sendo que a seção de mineralogia viria em catálogo separado) e uma Biblioteca Pública. Vale ainda ressaltar a presença de pesquisadores nacionais e estrangeiros no Museu, como por exemplo Orville Derby, da Comissão Geográfica e Geológica de São Paulo e Per Karl Dusen, da Academia Real Sueca das Ciências.

E interessante notar juntamente com Schwarcz que, no momento da instalação dos primeiros museus "modernos" (sic) no pais, o Brasil já era, há muito, objeto de coleçōes e análises de instituiçōes estrangeiras. Não é de estranhar, pois, que a criação dos museus brasileiros se dê concomitantemente à vinda de cientistas estrangeiros ao Brasil; tal é o caso, entre outros, de Carlos Frederico Hartt, Emilio Goeldi e Hermann von Ihering. Interessante também é constatar uma certa uniformidade no percurso científico dos museus brasileiros: João Batista de Lacerda, Hermann von Ihering, Emílio Goeldi são importantes administradores do Museu Nacional, Museu Paulista e Museu Paraense, respectivamente: os três estão à frente de seus museus no mesmo periodo (1893-1916).

Ao discorrer sobre o Museu Nacional, Schwarcz detém-se na análise da revista do mesmo, reiterando suas afirmaçōes anteriores de importação de teorias da Europa e dos Estados Unidos, atividades voltadas para as ciências naturais. Nota a autora a caracteristica nacionalista deste museu, ligado ao poder central (imperial e depois federal), que apenas aceitava cientistas brasileiros (Schwarcz, 1989:32).

Ao tratar do Museu Paulista, o texto confunde a questão da construção de um monumento comemorativo no local do Grito do Ipiranga, com a edificação de um museu em São Paulo. Diz a autora: "segundo a História Oficial (sic), a criação de um museu esteve a principio ligada à idéia de se erguer um monumento escultural e grandioso em homenagem à Independência Nacional" (Schwarcz, 1989:39). Não há no texto referências às propostas de monumentos comemorativos à Independência desde 1824, que se concretizaram na construção de um palácio na década de oitenta do século XIX. Mais adiante, escreve que "houve dificuldades em implementar o projeto de Tommaso Gaudencio Bezzi em razão do fato de a elite local não perceber
(...) o sentido prático nesse centro de estudos" (Schwarcz, 1989:40). A autora dá grande ênfase à construção de um monumento arquitetônico enquanto criação de um centro de estudos. No entanto, na documentação que registra as preocupaçōes de se construir este marco transparece a necessidade da sociedade brasileira da segunda metade do século XIX em fixar visualmente e, portanto, materialmente, o momento da fundação da Nação; discussões sobre a utilização do edifício-monumento são desdobramentos da questão.

Novos equivocos se repetem quando Schwarcz afirma que, estando o prédio desocupado por "não oferecer condições para o funcionamento normal de uma escola", o Museu Paulista "cumpria (...) apenas o papel de monumento histórico (...)". A seguir, informa que o Museu Paulista " (...) adquiriu as coleções pertencentes a Joaquim Sertório, localizadas no Museu do Estado (...)". Esta afirmativa levaria ao risco de confundir o leitor, que poderia não perceber que, na realidade, o Museu Paulista é o próprio Museu do Estado. Esse último havia surgido a partir da reunião da coleção Sertório e das coleçōes do Museu Provincial - criado pela Sociedade Auxiliadora para o Progresso da Provincia de São Paulo e entregue ao governo provincial em 1877. Mais tarde, com a República, o Museu Provincial passa a ser o Museu do Estado e, com a Lei no 200 de 28 de agosto de 1893, o Museu do Estado passa a ser Museu Paulista, assegurando ao acervo o direito de ocupação do edificio construido para ser um monumento à Independência. Em face desses detalhes, poder-se-ia considerar que a autora teria sido vitima da complexa trama que envolveu a criação do Museu do Estado, sua organização por von Ihering e a concomitante transferência do Museu para o prédio abandonado do Monumento do Ipiranga, este também de tumultuada história.

Outro equivoco seria considerar o núcleo formador do Museu constituido por porcelanas, cristais e móveis (Schwarcz, 1989:56) . Estas coleções, longe de se limitarem a esses elementos (que somente com a vinda do historiador Affonso de E. Taunay serão acrescentados ao acervo do Museu), são descritas por Koseritz quando de sua visita ao Museu Sertório (Koseritz, 1972:251-253).

Quanto ao funcionamento do Museu Pau- 
lista, o texto traz à tona questōes bastante interessantes para sua história, quando trata do personalismo de von Ihering, de sua animosidade com o Museu Nacional, da presença maciça de cientistas estrangeiros nas páginas da Revista do Museu Paulista e do que significou para os cientistas brasileiros a figura de Affonso de Escragnolle Taunay.

Ao afirmar que o museu de von Ihering "preenchia todos os requisitos formais anteriores que seus mestres lhe impunham, sem a minima condição de viabilizá-los" (Schwarcz, 1989:59), certamente não teria levado em conta as expediçōes realizadas no periodo de von Ihering, a Estação Biológica do Alto da Serra, o Horto Botânico plantado em área localizada na parte posterior do Monumento. Referindose ao Monumento do Ipiranga, o texto indica que von Thering não teria conseguido viabilizar os seus projetos, contrariando o que a documentaçāo do periodo (Revista do Museu Paulista, relatórios, etc.) parece demonstrar.

Ao final, deparamos com uma nova questão contraditória. Afirma a autora que "em seus momentos de nascimento, os estabelecimentos locais só contariam com um aspecto unificador: o próprio nome 'museu', que encobria projetos absolutamente diversos" (Schwarcz, 1989:56). Quando confirma esta afirmativa, diz que o Museu Nacional é fruto de um projeto descolonizador de D. João VI e que o Museu Paulista e o Museu Paraense têm gênese idêntica... ${ }^{3}$

Há, na verdade, o projeto da camada dominante que os convoca. $O$ texto peca por não definir claramente o que entende por "projeto". Depois desta distinçāo imprescindivel, nota-se que os projetos dos três museus brasileiros são muito parecidos: nascem da necessidade de uma parcela da classe dominante afirmar-se enquanto tal, ostentando sua riqueza e saber. Uma elite ilustrada, onde ter articulaçōes com centros de estudo, patrociná-los em suas gestōes políticas, acrescentar-lhe-ia signos de status. Neste contexto, autores como Renato Ortiz e Francisco Foot Hardman analisam a postura dessa elite brasileira dos fins do século XIX que, preocupada com a moder-

(3) Quanto à questàu do Museu Nacional, sugerimos mais uma vez a leitura do texto de Waldisa Rússio, "Existe um passado museológico brasileiro?"* nidade, com o progresso, tentará rodear-se das várias expressōes do "moderno": desde a construção de ferrovias até a produçāo de ciência (Ortiz, 1986; Hardman, 1991). É o caso das oligarquias do café (São Paulo) e da borracha (Pará). Os projetos são idênticos $\mathrm{e}$ não diversos.

No que toca à decadência dos Museus de Ciências Naturais no Brasil, foram relacionadas três circunstâncias. Uma delas está ligada à derrocada da escola evolucionista, o que incorreria no risco de se retirar o sentido do estudo sobre o processo histórico de transformação da natureza: se ela evolui, não pode ser determinada; ${ }^{4}$ outra, mais consistente, diz respeito ao desenvolvimento das ciências aplicadas, o que privilegia as Instituições a elas voltadas. Seria o caso do Instituto Agronômico de Campinas, Instituto Manguinhos, no Rio de Janeiro, citados por Schwarcz, mas também do Instituto Butantã, do Instituto Biológico de Defesa Animal, em São Paulo, e da Escola Agricola Luiz de Queiroz, em Piracicaba. Uma terceira, refere-se à ascensão das Universidades, notadamente a de São Paulo, como fóruns de construção do saber universalizante, fazendo dos Museus de Ciência Natural Pura seu apêndice, como é o caso do Museu Paulista (Schwarcz, 1989:56).

Analisar os museus significa também compreender o acervo, as exposiçōes e sua produção científica a partir dessas coleções. Uma observação desta natureza nos leva a perceber que, enquanto o Museu Nacional tinha uma postura racista, extremamente etnocêntrica, voltada à antropologia física de inspiração francesa, tão bem representada nas obras de um Paul Brocard, Quatrefages etc., o Museu Paulista não estava preocupado com dados craniométricos, mas com uma abordagem voltada essencialmente à confeç̧ão de registros etnográficos, com destaque a itens da cultura material, procurando dar conta da universalidade e diversidade das técnicas, das institui-

(4) Assim, o Museu Paulista figurou desde a criação da USP (25/1/1934) na relaçāo das Instituiçōes que deveriam concorrer para ampliar o ensino e ação na Universidade (artigo 49): “... i - Museu de Arqueologia, História e Etnografia que é o Museu Paulista“, considerado instituição complementar da USP, com representaçào no ConseIho Universitário. Emesto de Souza Campos, História da Universidade de São Pqulo, p. 114. 
ções e dos comportamentos das sociedades ditas primitivas. Ora com um viés evolucionista, ora com um viés difusionista.

Neste contexto, pode-se entender a abordagem sobre o racismo na produção cientifica do Brasil, durante este período. As críticas de Schwarcz, por exemplo, à importância do Museu Nacional para os estudos de craniometria, deixaram de levar em conta a relevância que este assunto tinha também na Europa de então, em especial na França.

No mesmo texto, sempre na tônica de quem se propōe a analisar os museus etnográficos - apesar de o título ser outro - faz uma estatistica das suas publicações. Quando escreve "museus etnográficos", referindo-se a Museu Nacional, Museu Paraense de História (futuro Museu Paraense Emilio Goeldi) e Museu Paulista - os "museus etnográficos locais" - , retrata apenas parcialmente a realidade das instituições, naquele momento. Nem o Museu Nacional nem o Museu Emilio Goeldi ou o Museu Paulista foram somente museus etnográficos. Tal como ocorria em todos os grandes museus da época, seus acervos eram muito diversificados, englobando além das coleçōes etnogrảficas, coleções zoológicas, coleçōes de botânica, coleções mineralógicas e coleçōes de História e Numismática. Apesar disso, devido às razōes da própria política do país, em certos momentos de sua história, esses museus receberam grandes coleções etnográficas, como por exemplo o Museu Nacional, que recebeu o material coletado pela Comissão Rondon, em parte também destinada à Comissão Geográfica e Geológica de São Paulo. $^{5}$

Da mesma maneira, a forma como a autora descreve os museus carece de informações sobre a apresentação das sociedades indígenas brasileiras nas exposiçōes. Na realidade, a autora não utiliza as exposições como fonte para sua pesquisa, embora estas sejam documentos essenciais para a compreensão dos museus. Percebe-se a importância que estes eventos vão ter desde a confecção de catálogos para os visitantes - lembramos o do Museu Paranaense de 1900 -, até as grandes exposiçōes, como é o caso da Exposição An-

(5) Ver os relatórios da Comissão Geográfica e Geológica de São Paulo do final do século XIX até 1910. tropológica Brasileira de 1882. Estas exposiçōes de fins do século XIX e inicios do século XX são a melhor expressão do caráter enciclopédico dos museus: arcos, flechas, arte plumária, minerais, quadros históricos etc., que se reúnem em um mesmo espaço, com o objetivo de transmitir conhecimentos e constituir veículo pedagógico. As várias fotografias destas exposiçōes consistem em riquissimo material de análise.

Um fato importante, ao qual a autora se refere en passant, talvez em função de constar na Revista do Museu Paulista apenas enquanto relatórios das diversas seçōes do Museu, compreende o contato intensivo e mesmo a prestação de serviços a esta Instituição, por arqueólogos e etnólogos estrangeiros ou recém-radicados no Brasil. No tocante à etnologia, ainda da época de von Ihering, destacase a presença - breve, é verdade - de Curt Nimuendajú, contratado para estudar os Guaranis em São Paulo. $O$ interesse pelo colecionismo e pelo inventário ergológico das sociedades tribais brasileiras fica bastante evidenciado, por exemplo, na aquisição da preciosa coleção Karajá e Javaé carreada ao Museu Paulista por Franz Adam, camarada de viagem de Fritz Krause em sua conhecida expedição ao Araguaia. Este mesmo interesse também se reflete na promoção de expedições que muitas vezes transcendem o desejo manifesto de adquirir "espécimes naturais". É o caso da viagem de Ernest e Walter Garbe aos Botocudos do Rio Doce, na primeira década deste século, cujo relatório acompanhado de farta documentação fotográfica é transformado em trabalho originalissimo por von Ihering e publicado na mencionada Revista, momentos após a completa descaracterização desta etnia. Walter Garbe encontrou um pequeno grupo de Botocudos que ainda conservava os costumes antigos, descritos por Paul Ehrenreich, que esteve com eles em 1884. A sua coleta entre os Botocudos parece ser bastante sistemática e traz ao Museu Paulista um elenco de objetos que alcança um amplo espectro desse repertório ergológico. A escolha não dependeu da curiosidade da indumentária ou dos instrumentos musicais, mas do significado desses objetos no contexto da cultura material. Outro lado interessante, provavelmente não consultado para a elaboração do texto em questão, é o noticiário da vinda de Edgard 
Roquette Pinto ao Museu, em 1918 (já na gestão do historiador Affonso de E. Taunay), para organizar e proceder a um catálogo sistemático das coleções etnográficas ali alocadas, material este originalmente pertencente ao $\mathrm{Mu}$ seu Nacional, reunido pela Comissão de Linhas Telegráficas (Comissão Rondon).

Ao tratar da saida de von Thering da direção do Museu Paulista em 1916, Schwarcz afirma que esta teria origem na polêmica criada em torno de suas declaraçōes sobre o exterminio dos índios (1908). Não há dúvida de que, provavelmente, a saída de von Ihering estivesse ligada ao crescente nacionalismo desenvolvido no contexto da Primeira Grande Guerra, que tornava insustentável a situação de um cientista alemão à frente de uma Instituição programada para ser o símbolo da nacionalidade. Um segundo motivo seria a orientação de von Thering ao Museu Paulista, não correspondendo aos anseios da elite governante, que pretendia nele ver perpetuada a memória da Independência: o projeto mais desenvolvido trazia a zoologia como prioridade, preterindo o crescimento das coleções de história. Isto sim teria mais peso no afastamento de von Ihering, do que suas declaraçōes sobre o extermínio de indios, que ocorrera oito anos antes do seu afastamento efetivo (longo periodo!), exterminio, aliás, que a fundação do Serviço de Pro- teção aos Indios pôs fim. ${ }^{6}$ Vale ainda lembrar que houve uma sindicância interna na Instituição pela Secretaria do Interior, quando von Ihering recebeu criticas contundentes à sua administração, culminando com a sua saída.

As divergências apontadas resultam, talvez, da opção feita por Schwarcz sobre as fontes de consulta, e o encaminhamento da análise. As publicações produzidas pelas Instituições dão, certamente, uma idéia da situação, de seus objetivos e de sua metodologia de trabalho. Mas, outras fontes teriam que ser analisadas para uma compreensão mais completa dos museus, enquanto instituiçōes produtoras de ciência e instrumentos de ação cultural e educacional. Consideramos, em primeiro lugar, a necessidade do exame do próprio acervo, seus programas cientificos, suas expediçōes científicas, suas exposiçōes e sua atuação pedagógica, a correspondência de seu corpo administrativo e ainda uma visão da comunidade acadêmica a seu respeito.

Naturalmente, seriam muitas exigências a cumprir para que suas respostas pudessem ficar dimensionadas nos limites de um artigo. No entanto, o texto em questão, certamente, contribuiu de forma substancial, ao cuidar da Instituição Museu como um produto histórico de uma vontade de fazer ciência e abrir o diálogo a respeito do tema.

\section{Referências bibliográficas}

AZEVEDO, F. (Intr. e org.). As Ciências no Brasil. São Paulo, Melhoramentos, 1966.

CAMPOS, E. de Souza. História da Universidade de São Paulo. São Paulo, 1954.

GAGLIARDI, J. M. O Indigena e a República. São Paulo, Ed. Hucitec/Edusp/Secretaria de Estado da Cultura de Sāo Paulo, 1989.

GUARNIERI, W. Russio. Existe um Passado Museológico Brasileiro? O Estado de São Paulo. Suplemento Literário, 22/7/1979.

HAMY, E-T. Les Origines du Musée d'Ethnographie, Les Cahiers Gradhiva 7. Paris, Editions Jean-Michel Place, 1988.

—. La Muséologie selon G. H. RIVIERE, Bordas Dunot, 1989.

(6) Um excelente acompanhamento sobre essas questões estāo na obra de José Mauro Gagliardi, $O$ Indígena e a República.
HARDMAN, F. Foot. Trem Fantasma e Modernidade na Selva. São Paulo, Companhia das Letras, 1991.

IMPEY, O. \& A. MACGREGOR (Eds.). The Origins of Museums - The Cabinets of Curiosities in Sixteenth and Seventeenth Centuries in Europe. Oxford, Clarendon Press, 1985.

KOSERITZ, C. von. Imagens do Brasil. Sāo Paulo, Martins/Universidade de São Paulo, 1972.

MARTINS, W. História da Inteligência Brasileira. São Paulo, Cultrix/Edusp, 1977.

MICELI, S. (Org.). História das Ciências Sociais no Brasil. Sảo Paulo, Ed. Vértice, 1989.

MORLEY, G. L. Mac Cann. Les Musées en Amerique Latine, Museum, vol. XII, 4:254-271, 1959.

—. Aspectos da Política Cultural Brasileira, ediçāo do Conselho Federal de Cultura. Rio de Janeiro, 1976 (conforme citação de Waldisa Rússio em artigo publicado pelo Suplemento Literário de $O E s-$ tado de São Paulo em 22/07/1979). 